reprovision programmes in Britain, provided that these are well planned and well resourced.

\section{Conclusion}

Our findings dispel some of the common concerns and myths associated with "care in the community" patients and provide robust evidence that community care has worked well for the former patients of psychiatric hospitals, most of whom are currently living in the community and posing minimal risk to themselves and the public. In light of this, a change towards institutional care is not a rational policy.

We thank the research workers who have contributed to the collection of the data, the patients, and the hospital and community staff. This paper is designated the TAPS project 45 .

Contributors: NT participated in data collection, analysis, interpretation, and drafting the paper. JL conceived and designed the Team for the Assessment of Psychiatric Services (TAPS) project and has been the director of the research team for the past 13 years. He helped to draft and edit this paper. GG participated in the analysis and interpretation of the mortality data. He also computerised the assessment tools used by TAPS. NT and JL will act as guarantors for the paper.

Funding: The Team for the Assessment of Psychiatric Services (TAPS) is funded by the Department of Health, North Thames Regional Health Authority, and the Gatsby Foundation. It is administered through the Department of Psychiatry and Behavioural Sciences, Royal Free and University College Medical School, London.

Competing interests: The TAPS project was largely funded by the Department of Health. This, and previous TAPS papers, were sent for comments to the Department of Health before submission. However, all papers, including this one, were drafted without administrative intervention or scrutiny of any kind. The opinions expressed do not necessarily reflect the policy of the Department of Health.

1 Weller MP. Mental illness-who cares? Nature 1989;339:249-52

2 O'Driscoll C, Wills W, Leff J, Margolius O. The TAPS project 10: the longstay populations of Friern and Claybury hospitals - the baseline survey. $\mathrm{Br}$ JPsychiatry 1993;162(suppl 19):30-5.

3 Trieman N, Leff J. The difficult to place patients in a psychiatric hospital closure programme. The TAPS project 24. Psychol Med 1996;26:765-74.

4 Trieman N, Leff J. The TAPS project 36: the most difficult to place longstay psychiatric inpatients: outcomes one year after relocation. $\mathrm{Br} J$ Psychiatry 1996;169:289-92

5 O'Driscoll C, Leff J. The TAPS project 8: design of the research study on the long-stay patients. Br J Psychiatry 1993;162(suppl 19):18-24

6 Leff J, Trieman N, Gooch C. The TAPS project 33: a prospective follow-up study of long-stay patients discharged from two psychiatric hospitals. Am J Psychiatry 1996:153:1318-24

7 Leff J, Thornicroft G, Coxhead N, Crawford C. The TAPS project 22: a five year follow-up of long-stay psychiatric patients discharged to the community. Br J Psychiatry 1994;165(suppl 25):13-7.

8 Jones D. The TAPS project 11: the selection of patients for reprovision. $\mathrm{Br}$ J Psychiatry 1993;162(suppl 19):36-9.

9 Gooch C, Leff J. Factors affecting the success of community placement. The TAPS project 26. Psychol Med 1996;26:511-20.

10 Houghland G, Craig TM, Goodman AB. Mortality in the era of deinstitutionalization. Am J Psychiatry 1983;140:848-52.

11 Lamb HR. Lessons learned from deinstitutionalization in the US. $\mathrm{Br} J$ Psychiatry 1993;162:587-90.

12 Timms PW, Fry AH. Homelessness and mental illness. Health Trends 1989;21:70-1.

13 King's Fund Report. London's mental health. London: King's Fund, 1997.

14 Modestin J, Ammann R. Mental disorders and criminal behaviour. $\mathrm{Br}$ J Psychiatry 1995;166:667-75.

15 Harris EC, Baraclough B. Excess mortality of mental disorder. $\mathrm{Br} J$ Psychiatry 1998;173:11-53.

16 Hazel M, Inskip E, Harris C, Barraclough B. Lifetime risk of suicide for affective disorders, alcoholism and schizophrenia. $\mathrm{Br} J$ Psychiatry 1998;172:35-7.

17 Clifford P, Charman A, Webb Y, Best S. Planning for community care: long-stay populations of hospitals scheduled for rundown or closure. $\mathrm{BrJ}$ Psychiatry 1991:158:190-6.

18 Trieman N, Leff J. The TAPS project 42: the last to leave hospital-a profile of residual long-stay populations and plans for their resettlement. Acta Psychiatr Scand 1998;98:354-9.

(Accepted 30 March 1999)

\title{
Serious hazards of transfusion (SHOT) initiative: analysis of the first two annual reports
}

\author{
L M Williamson, S Lowe, E M Love, H Cohen, K Soldan, D B L McClelland, P Skacel, J A J Barbara
}

National Blood Service East Anglia/University of Cambridge Division of Transfusion Medicine, Cambridge CB2 2PT

L M Williamson, lecturer/consultant in transfusion medicine

National Blood

Service Manchester,

Manchester

M13 9LL

S Lowe,

SHOT assistant

national coordinator

E M Love,

consultant

haematologist

University College London Hospitals, London

WC1E 6DB

H Cohen,

consultant in

haematology

continued over

BMJ 1999;319:16-9

\author{
Abstract \\ Objective To receive and collate reports of death or \\ major complications of transfusion of blood or \\ components. \\ Design Haematologists were invited confidentially to \\ report deaths and major complications after blood \\ transfusion during October 1996 to September 1998. \\ Setting Hospitals in United Kingdom and Ireland. \\ Subjects Patients who died or experienced serious \\ complications, as defined below, associated with \\ transfusion of red cells, platelets, fresh frozen plasma, \\ or cryoprecipitate. \\ Main outcome measures Death, "wrong" blood \\ transfused to patient, acute and delayed transfusion \\ reactions, transfusion related acute lung injury, \\ transfusion associated graft versus host disease, \\ post-transfusion purpura, and infection transmitted \\ by transfusion. Circumstances relating to these cases \\ and relative frequency of complications. \\ Results Over 24 months, 366 cases were reported, of \\ which 191 (52\%) were "wrong blood to patient" \\ episodes. Analysis of these revealed multiple errors of \\ identification, often beginning when blood was \\ collected from the blood bank. There were 22 deaths
}

from all causes, including three from $\mathrm{ABO}$ incompatibility. There were 12 infections: four bacterial (one fatal), seven viral, and one fatal case of malaria. During the second 12 months, 164/424 hospitals (39\%) submitted a "nil to report" return. Conclusions Transfusion is now extremely safe, but vigilance is needed to ensure correct identification of blood and patient. Staff education should include awareness of $\mathrm{ABO}$ incompatibility and bacterial contamination as causes of life threatening reactions to blood.

\section{Introduction}

The current incidence of major complications due to blood transfusion is unknown. Until 1996 blood transfusion was not covered by either a confidential inquiry or the yellow card system of the Committee of Safety of Medicines. Perception of transfusion safety focuses on the diminishing risk of viral transmission, while the risk of $\mathrm{ABO}$ incompatible transfusion due to errors in blood or patient identification remains a threat. ${ }^{12}$ To analyse the residual risks of transfusion, a confidential voluntary reporting system for major transfusion events-serious hazards of transfusion (SHOT)- 
Morbidity and mortality related to transfusions in fully analysed cases $(n=341)$

\begin{tabular}{lcccccrrr} 
Detail & Total & $\begin{array}{c}\text { Incorrect } \\
\text { component } \\
\text { transfused }\end{array}$ & $\begin{array}{c}\text { Major acute } \\
\text { transfusion } \\
\text { reaction }\end{array}$ & $\begin{array}{c}\text { Major delayed } \\
\text { transfusion } \\
\text { reaction }\end{array}$ & $\begin{array}{c}\text { Post- } \\
\text { transfusion } \\
\text { purpura }\end{array}$ & $\begin{array}{c}\text { Graft versus } \\
\text { host disease }\end{array}$ & $\begin{array}{c}\text { Transfusion } \\
\text { related acute } \\
\text { lung injury }\end{array}$ & $\begin{array}{c}\text { Transfusion } \\
\text { transmitted } \\
\text { infections }\end{array}$ \\
\hline Death attributed to transfusion & 22 & 3 & 1 & 3 & 1 & 8 & 4 \\
\hline Major morbidity & 84 & $32 †$ & 2 & 16 & 5 & 0 & 19 \\
\hline Minor/no morbidity & 235 & 141 & 47 & 31 & 16 & 0 & 0 \\
\hline Total & 341 & 176 & 50 & 50 & 22 & 8 & 23 \\
\hline
\end{tabular}

*Admission to intensive care or ventilation, or both; dialysis or renal dysfunction, or both; major haemorrhage; jaundice including intravascular haemolysis; persistent viral infection; acute symptomatic confirmed infection.

†Includes six cases of potential rhesus sensitisation in young women/girls.

affiliated to the Royal College of Pathologists was launched in 1996. We have summarised the main findings from its first two annual reports.

\section{Methods for case ascertainment}

In November 1996 haematologists in the United Kingdom and Ireland were invited on a voluntary confidential basis to inform SHOT of deaths and major adverse events in seven categories (see results) associated with the transfusion of red cells, platelets, fresh frozen plasma, or cryoprecipitate. The SHOT launch was publicised at professional conferences and by an editorial in the $B M J .{ }^{3}$ Suspected cases of post-transfusion infection were reported to local blood centres, and cases confirmed after donor investigation as related to transfusion were collated by the National Blood Authority/Public Health Laboratory Service Communicable Disease Surveillance Centre.

Incidents other than infections reported to the SHOT office were analysed with a questionnaire then entered on a secure database without identifiers. During the second year hospitals could submit a "nil to report" return card. We have analysed data relating to incidents that occurred between 1 October 1996 and 30 September 1998.

\section{Results}

\section{Overview}

Of 424 eligible hospitals, 94 submitted 169 reports during the first year, with 112 hospitals submitting 197 reports during the second year, an increase of $16.5 \%$. "Nil to report" cards, introduced in the second year, were submitted by 164 hospitals (39\%), bringing overall participation to $65 \%$. Reports included 191 incidents of incorrect blood transfused and 12 infections transmitted by transfusion (figure). Of 341 analysed cases, there were 22 deaths and 81 cases of major morbidity, with at least one death in every category (table).

\section{Incorrect blood or component transfused}

Of the 191 reported episodes in which a patient was transfused with a wrong blood component, 62 were $\mathrm{ABO}$ incompatible transfusions, leading to three deaths, 25 cases requiring intensive care, and six cases of potential rhesus D sensitisation in young female patients. The errors in 177 analysed cases of incorrect transfusion generally consisted of a sequence of one to seven failures to detect incorrect identity of blood or patient, leading to transfusion to the wrong patient (one error-103 cases; two errors-40 cases; three errors-26 cases; four errors-2 cases; six errors- 5

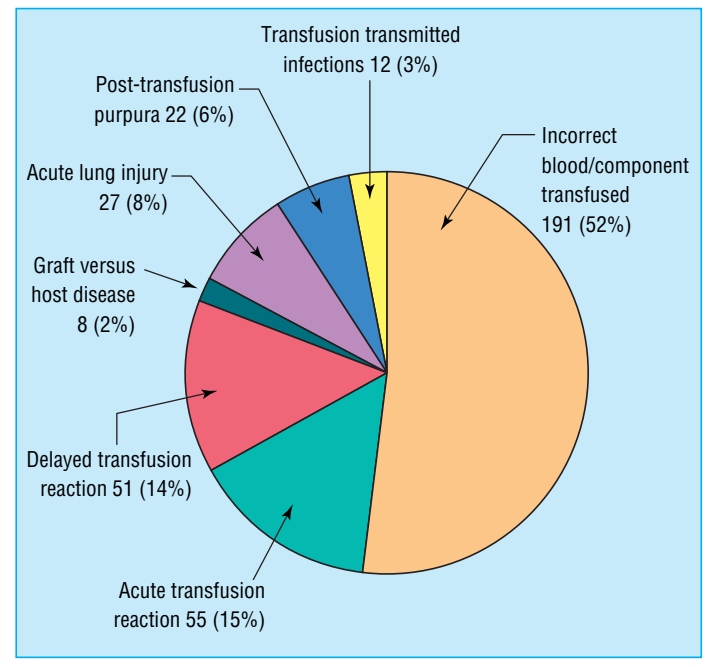

Overview of 366 cases for which initial report forms were received

cases; seven errors-1 case). First errors occurred at all stages of the process: during the request for blood or sampling of the patient, or both (33), including two incidents (one fatal) of transposition of blood grouping samples at the patient's bedside, and in the transfusion laboratory (59). Collection of the wrong blood from the blood bank refrigerator was the major source of primary error (61), with blood frequently taken without a formal identity check against the patient's case record. The bedside check failed to detect discrepancy in blood or patient identity in a total of 80 cases, despite being carried out by two people (one always a qualified nurse or doctor). In 20 incidents, the patient had no identity wrist band.

\section{Immunological interactions between donor and patient}

Immunological interactions were reported in five categories (acute and delayed reactions, posttransfusion purpura, transfusion associated graft versus host disease, and transfusion related acute lung injury). These cases were unpredictable and generally did not represent poor practice. In two cases, however, haemolytic antibodies were missed because of noncompliance with current guidelines. ${ }^{4}$ Occasionally, relevant information was not available because the blood bank computer could not be accessed.

Five reports were received of a hypotensive reaction to components passed through a bedside leucocyte filter. ${ }^{5}$ Of eight cases of transfusion associated graft versus host disease, one was a premature neonate with an unusual form of immunodeficiency and four patients had B cell lymphoid malignancy, not currently an indication for prevention of transfusion associated
National Blood Service, Public

Health Laboratory

Service

Communicable

Disease

Surveillance Centre

Colindale, London

NW9 5EQ

K Soldan,

infection surveillance

officer

Edinburgh and

South East Scotland

Blood Transfusion

Service,

Department of

Transfusion

Medicine, Royal

Infirmary,

Edinburgh

EH3 9HB

D B L McClelland,

director

Royal Postgraduate

Medical School,

Hammersmith

Hospital, London

W12 OHS

P Skacel,

senior lecturer in

haematology

National Blood

Service, Colindale,

London NW9 5BG

J A J Barbara,

microbiology

consultant to

National Blood

Authority

Correspondence to:

L M Williamson

lorna.williamson@

nbs.nhs.uk 


\section{Summary of main findings and recommendations}

\section{Finding}

Prelabelled cross match sample tubes are a source of misidentity

Request for blood may omit special requirements, especially over the telephone

Previous transfusion information was not always used in decision making

Blood bank errors in grouping, cross matching, and labelling were found

The most important primary cause of error was in collecting blood from the blood bank Lack of patient wristbands or other identifiers was a source of wrong blood being transfused Earlier errors are not being detected at the final bedside check, even if two qualified staff check the blood

Local systems for staff training and oversight of transfusion practice are variable

Several organisations are responsible for decision making in transfusion safety

Investigation of transfusion reactions was

variable and may have led to underestimation of

bacterial transmission
Recommendation

Current BCSH guideline recommends labelling at the bedside after the sample is drawn

Request systems must ensure that all requirements are met and that responsibilities of ward and blood bank staff are clear

Previous transfusion records should be available at all times and blood groups checked with current results

Blood banks should review procedures for adherence to national guidelines and ensure ongoing staff training

Hospitals should review current procedures and define minimum identification requirements. Novel IT systems merit evaluation Procedures to ensure correct patient identification are particularly important in theatre and for outpatient transfusions

$\mathrm{BCSH}$ will produce a national guideline to cover this issue; hospitals will be responsible for implementation and staff training

Every hospital should have a transfusion committee with responsibility for all matters related to transfusions

A unified approach to setting priorities for transfusion safety would ensure best use of resources

Standardised protocols for joint investigation of suspected bacterial sepsis and immunological reactions between hospitals and blood centres would be helpful graft versus host disease by the use of $\gamma$ irradiated blood components.

\section{Transfusion transmitted infection}

Twelve of 60 suspected cases (20\%) were confirmed to be related to the transfusion. Six cases (one hepatitis A infection, one malaria, four bacteraemias) were due to infections for which no testing of donations is performed, while five cases (three hepatitis $\mathrm{B}$, one hepatitis C, one HIV) were due to donations from repeat donors during marker negative "window periods" after recent infection. A further newly reported case of infection with hepatitis $\mathrm{C}$ virus was in a patient who received a transfusion before the introduction of donor screening in 1991. The HIV transmission involved components from one donor transfused to three different recipients. The three nonfatal bacterial incidents involved red cells contaminated with Serratia liquefaciens, platelets containing Escherichia coli, and leucocyte depleted platelets containing Bacillus cereus, also grown from the donor's arm. Fatal septicaemia due to Staphylococcus aureus occurred in one platelet recipient. $S$ aureus was also isolated from the donor's skin and nose.

The other fatality caused by infection was due to cerebral malaria after transmission of Plasmodium falciparum from a donor who lived in a malarious area as a child and who had revisited a (different) malarious area within the previous 4 years. This has already led to amendments to selection criteria for donors.

\section{Key recommendations and feedback}

Major findings and the recommendations arising from them are summarised in the box. Detailed annual reports were sent to all haematologists, ${ }^{67}$ with a summary to trusts' chief executives and blood bank managers. Seventy nine hospitals had already reviewed procedures for blood handling and staff training after the incident reported. The SHOT findings were highlighted at a transfusion seminar organised by the United Kingdom chief medical officers, and participation in SHOT was recommended in a health service circular to trusts. ${ }^{8}$

\section{Discussion}

Voluntary reporting of serious complications of transfusion has its limitations-we may be seeing only the tip of the iceberg, viral infections may present years after acquisition, and there are no denominators from which to calculate hazard incidence. The incidence of $\mathrm{ABO}$ incompatible transfusions reported here (62 in 2 years), however, is not significantly different from that seen in the French haemovigilance system (58 in 3 years), to which reporting is mandatory. ${ }^{9}$ In the second year, SHOT implemented a nil to report card; this revealed that the $65 \%$ of participating hospitals handled $70 \%$ of all red cells issued in the United Kingdom. SHOT findings therefore do seem representative of transfusion practice.

\section{Key messages}

- Blood transfusion, while extremely safe, has several potentially fatal hazards

- All staff handling blood should be aware of the importance of correct identity of sample, patient, and blood bag at all stages

- Resources should be directed to evaluation of methods for improving identification of patients

- Acute fever or collapse during or after transfusion may be due to $\mathrm{ABO}$ incompatibility or bacterial contamination

- Microbiological complications of transfusion accounted for a minor component of all reports 
The two annual reports have provided the first detailed analysis of transfusion errors in the United Kingdom, an approach already recommended in the United States. ${ }^{10}$ Following defined procedures for blood handling ${ }^{11}$ and regular staff training are crucial; bedside $\mathrm{ABO}$ grouping has a high error rate ${ }^{12}$ and is not recommended by SHOT, although it is mandated in France. Medical and nursing staff must be aware of the possibility of $\mathrm{ABO}$ incompatibility or bacterial infection in a shocked recipient of transfusion, while errors in identification will be minimised by procedural training for porters and phlebotomists and by forthcoming guidelines for blood handling and administration from the British Committee for Standards in Haematology. Infections transmitted by transfusion were relatively rare, a finding consistent with the calculated low residual viral risk, ${ }^{13}$ now overtaken by the frequency of bacterial contamination of platelet concentrates. ${ }^{14}$ SHOT data provide mixed messages: the risk:benefit ratio of appropriate transfusion is high compared with other risks in life, ${ }^{15}$ but safety can still be improved. The United Kingdom lacks a unified body to take an overview of all aspects of blood safety, sometimes making it difficult to practise "aligning effort with risks." ${ }^{16}$ Technological advances such as viral genomic detection and inactivation may be mandated by regulatory authorities, but prevention of transfusion error requires local managerial commitment, "process re-engineering," ${ }^{17}$ and an active hospital transfusion committee. Hopefully the concept of clinical governance will focus resources in this important area.

Contributors: LMW, EML, PS, and JAJB took part in the establishment of the SHOT scheme, design of the questionnaire, analysis of data, and compilation of the report. SL, HC, and KS took part in design of the questionnaire, analysis of data, and compilation of the report. DBLMcC took part in the establishment of the SHOT scheme, analysis of data, and compilation of the report. LMW, HC, and EML are the guarantors.

Funding: UK Transfusion Services, Republic of Ireland Transfusion Service, British Society for Haematology, British Transfusion Society.

Competing interests: None declared.

1 Sazama K. Reports of 355 transfusion-associated deaths: 1976 through 1985. Transfusion 1990;30:583-90.

McClelland DBL, Phillips P. Errors in blood transfusion in Britain: survey of hospital haematology departments. BMJ 1994;308:1205-6.

3 Williamson LM, Heptonstall J, Soldan K. A SHOT in the arm for safer blood transfusion. BMJ 1996;313:1221-2.

4 BCSH Blood Transfusion Task Force. Guidelines for pre-transfusion compatibility procedures in blood transfusion laboratories. Transfusion Medicine 1996;6:273-83.

5 Shiba MK, Tadokoron K, Sawanobori M, Nakajima K, Suzuki K, Juji T Activation of the contact system by filtration of platelet concentrates with a negatively charged white cell-removal filter and measurement of venous blood bradykinin level in patients who received the filtered platelets. blood bradykinin level in pation 1997;37:457-62.
Transfusion

6 Williamson LM, Lowe S, Love EM, Cohen H, Soldan K, McClelland DBL, et al. SHOT annual report 1996-1997. Manchester: SHOT Office, Manchester Blood Centre, 1998.

7 Williamson LM, Lowe S, Love EM, Cohen H, Soldan K, McClelland DBI, et al. SHOT annual report 1997-1998. Manchester: SHOT Office, Manchester Blood Centre, 1999.

8 NHS Executive. Better blood transfusion. London: NHS Executive, 1999. (Circular HSC 1998/99.)

9 Centre National d'Hémovigilance. L'hémovigilance actualites et dossiers: lettre dinformation de l'Agence Française du sang en collaboration avec le Centre National d'Hémovigilance. Avril 1995 and Mars 1996. Paris: Agence Francaise du Sang, 1999.

10 Kaplan HS, Battles JB, Van der Schaaf TW, Shea CE, Mercer SQ. Identification and classification of the causes of events in transfusion medicine. Transfusion 1998;38:1071-81.

11 Lumadue JA, Boyd JS, Ness PM. Adherence to a strict specimen-labelling policy decreases the incidence of erroneous blood grouping of blood bank specimens. Transfusion 1997;37:1169-72.

12 Ingrand P, Surer-Pierres N, Houssay D, Salmi LR. Reliability of the pretransfusion bedside compatibility test: association with transfusion practice and training. Transfusion 1998;98:1030-6.

13 Schreiber GB, Busch MP, Kleinman SH, Korelitz JJ. The risk of transfusion-transmitted viral infections. $N$ Engl J Med 1996;334:1685-90. 14 Blajchman MA, Ali AM, Richardson HL. Bacterial contamination of cellular blood components. Vox Sang 1994;67:25-34.

15 Calman KC. Cancer: science and society and the communication of risk. BMJ 1996:313;799-802

16 AuBuchon JP, Kruskall MS. Transfusion safety; realigning efforts with risks. Transfusion 1997:37:1211-6.

17 McClelland DBL. Treating a sick process. Transfusion 1998;38:999-1103. (Accepted 19 April 1999)

\title{
Cost minimisation analysis of provision of oxygen at home: are the Drug Tariff guidelines cost effective?
}

\author{
Liam G Heaney, Denise McAllister, Joseph MacMahon
}

\begin{abstract}
Objectives To determine the level of oxygen cylinder use at which it becomes more cost effective to provide oxygen by concentrator at home in Northern Ireland, and to examine potential cost savings if cylinder use above this level had been replaced by concentrator in 1996.

Design Cost minimisation analysis.

Setting Area health boards in Northern Ireland. Main outcome measures Cost effective cut off point for switch to provision of oxygen from cylinder to concentrator. Potential maximum and minimum savings in Northern Ireland (sensitivity analysis) owing to switch to more cost effective strategy on the basis of provision of cylinders in 1996.

Results In Northern Ireland it is currently cost effective to provide oxygen by concentrator when the
\end{abstract}

patient is using three or more cylinders per month independent of the duration of the prescription. More widespread use of concentrators at this level of provision is likely to lead to a cost saving. Conclusions The Drug Tariff prescribing guidelines, advocating that provision of oxygen by concentrator becomes cheaper when 21 cylinders are being used per month-are currently inaccurate in Northern Ireland. Regional health authorities should review their current arrangements for provision of oxygen at home and perform a cost analysis to determine at what level it becomes more cost effective to provide oxygen by concentrator.

\section{Introduction}

In the United Kingdom, the provision of oxygen at home can be prescribed either in cylinders (capacity of
Department of Respiratory Medicine, Belfast City Hospital, Belfast BT9 7AB Liam G Heaney, senior registrar

Joseph MacMahon, consultant physician School of Public Policy and Law, University of Ulster, Jordanstown, Belfas Denise McAllister, professor

Correspondence to: Dr Heaney LiamHeaney@ ukgateway.net

BMJ 1999;319:19-23 